\title{
Pediococcus pentosaceus
}

National Cancer Institute

\section{Source}

National Cancer Institute. Pediococcus pentosaceus. NCI Thesaurus. Code C123539.

A species of Gram positive, facultatively anaerobic, non-motile, non-spore forming, cocci shaped bacterium in the family Lactobacillaceae. This species possesses a strictly fermentative metabolism with lactic acid as the major metabolic end product. P. pentosaceus can be found in plant materials, ripened cheese, and a variety of processed meats. 